\title{
The Disembodied Librarian in the Digital Age, Part II
}

\section{Charles Martell, with responses to the article from Barbara Moran and Laverna Saunders}

\begin{abstract}
In the January issue of College \& Research Libraries, the author began a discussion of four profound historical discontinuities-time and space, mind and body, real and virtual, and humans and technology - that are reaching critical thresholds as we enter the twenty-first century. Existing within multiple environments-technological, social, and cultural, these discontinuities are seldom acknowledged, but their influence on the future of our institutions is incalculable. An awareness of these discontinuities will assist librarians in (1) creating a new virtual space for libraries as physical space becomes less important, (2) adapting to states of disembodiment caused by roles deeply embedded in virtual environments, and (3) developing the new value-added services necessary for survival in the next millennium. In part II of this discussion, these discontinuities are related to new ways of being and thinking about the future of librarians and libraries. This article is followed by responses from Barbara Moran and Laverna Saunders.
\end{abstract}

Our speech interposes itself between apprehension and truth like a dusty pane or warped mirror.

$\sim$ George Steiner

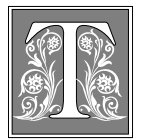

he discontinuities discussed in the first part of this article published in the January issue of $C \mathcal{E} R L$ are relevant to our personal and professional lives. In some cases, they will not be resolved satisfactorily, which may have serious consequences for society. In other cases, we will live with the problem and do the best we can. The consequences of this approach will be significant, but not disastrous.
Disembodiment in cyberspace, the creation of computer intelligence, and developments in genetic engineering will force humanity to consider directly the nature of being as a biological entity and as a species. The impact of these forces on our sense of self is incalculable.

In this section, pieces of the puzzle are examined a bit more closely. The purpose is to extract additional meaning and uncover patterns or linkages. Although the themes of time and space, mind and body, real and virtual, and humans and technology have been discussed separately in this article, they are largely inseparable. A few comments are made about writing

Charles Martell is a Librarian at California State University-Sacramento; e-mail: crmartell@csus.edu. Barbara Moran is a Professor in the School of Information and Library Sciences at the University of North Carolina at Chapel Hill. Laverna Saunders is the Dean of Library Instructional and Learning Support at Salem State College. 
space: the concept deserves greater attention at another time. Some major trends will be mentioned - trends likely to influence the behaviors and attitudes of future learners. Finally, a brief commentary on the prospects for coping with the primary discontinuities is included. The material in this section provides additional perspectives from which to view libraries in the future.

\section{A change in who represents the truth poses the greatest dilemma to those who currently represent the truth.}

The computer is to the book as the automobile is to the tricycle. The invention of the printing press transformed reading and writing; the computer is doing the same. According to Jay David Bolter, "an electronic text is a network rather than the straight line suggested by the pages of a printed book." ${ }^{1}$ In Hypertext: The Convergence of Contemporary Critical Theory and Technology, George P. Landow condensed the thinking of many who write on hypertext or literary theory by arguing "that we must abandon conceptual systems founded upon ideas of center, margin, hierarchy, and linearity and replace them with one of multilinearity, nodes, links, and networks. Almost all parties to this paradigm shift, which marks a revolution in human thought, see electronic writing as a direct response to the strengths and weaknesses of the printed book. This response has profound implications for literature, education, and politics." $^{2}$

Computers disclose invisible spaces where physical distance is irrelevant and computer time is beyond sensory recognition. The body as a physical entity is unimportant in cyberspace. The mind becomes all-important. Today, we may view the computer as an impersonal tool. Today, we may view immersion in the computer as virtual time. This will change with a quickness we will never see. We will wake up one day and the change will have occurred. Virtual life and real life will be joined into one vast experiential power- house. "Computer screens are the new location for our fantasies, both erotic and intellectual. We are using life on computer screens to become comfortable with new ways of thinking about evolution, relationships, sexuality, politics, and identity." 3

The reason for the swiftness of this change is simple. Our world consists of multiple virtual environments that we have already adopted into our lives as real. In many cases, the distinction between real and virtual may already be irrelevant. Media are virtual agents. Media depict the spectacle of life. This spectacle "no longer makes any pretense of representing reality; it has replaced reality." ${ }^{\prime 4}$ Entertainment values distort other values. When combined with a pervasive materialism, they form a powerful barrier against meaningful social and cultural change.

The fear of the loss of representational truth may partially explain the ardent defense of the book. Scott Bukatman broadens this perspective: "The perception of a spectacular assault on the dominance of written language stands revealed as a defense of pre-electronic representational forms (writing, photography, and even cinema) which actually reifies a pre-electronic, empirically verifiable definition of the 'real."' 5 Throughout history, representational truth has always been problematic. The interests and motives of those who are doing the representing are typically the rootstock of truth. A change in who represents the truth poses the greatest dilemma to those who currently represent the truth. A change poses significant opportunity to those who have not been able to but want to. For this and a wide range of other reasons, the problem of representational truth will continue to be of acute interest to many people.

The human need for the real or the true is strong. Other needs are equally strong. The history of the Age of Enlightenment teaches us that theological and metaphysical needs based on faith have frequently opposed scientific needs based on knowledge. Nevertheless, the shifting sands of reality and smoky mirrors of 
truth as expressed by the postmodernists must be disturbing to those who cherish the search for truth as a transcendent human endeavor. From this author's perspective, this problem will not abate in the years ahead but will become more urgent. Indeed, there is every indication that the business of entertainment subverts reality. Truth has become a commodity. Its preeminent value is commercial.

With the merging of imaging and computer technologies, vast new markets will be forged with products ranging from full immersion and presence experiences to supersensory human smell and tactile interfaces. ${ }^{6}$ Virtual and augmented reality, so dazzling to the twentieth-century imagination, will one day become commonplace. The distinctions created today will disappear through use. Most of the discontinuities we perceive will resolve themselves in the everyday struggle to get along and to enjoy life as best we can. On the other hand, resolving some of these discontinuities may take centuries. Thus it has been, and thus it will be.

\section{This author speculates that the number of rudimentary virtual reality learning tools will increase considerably in the next two de- cades.}

Some matters are more complicated. They thwart any attempt to be glib or to rely on historical antecedents. Computer intelligence (not artificial intelligence) and human cloning would be developments of earth-shattering magnitude. Their impact would stagger the imagination. They would undermine the core beliefs on which most civilizations have relied. Computer intelligence or human cloning would considerably exacerbate the primary discontinuities discussed in this article. Fortunately, the adaptations we are making to computers specifically and to technology more generally may help to narrow the gap between present-day belief structures and those required when the demand for a new ontology becomes inescapable. The mind and body and hu- mans and technology discontinuities appear to be the most crucial in a transformation of such magnitude. In a discussion of the Biotech Century, Jeremy Rifkin sounds a related warning: "The possibilities of programming genetic changes into the human gene line to direct the evolutionary development of future generations brings society to the precipice of a eugenics era with consequences-both to the biology of our species and to civilization-that are largely unpredictable and unknowable."

\section{Trends and Characteristics}

The rapid growth of the entertainment industry will continue. This is a mixed blessing. The blurring of the distinctions between the real and the virtual will be confusing. The pure joy and fun to be derived from the new forms of entertainment will render the negative features relatively insignificant in the public's imagination. The forbidden pleasure profits to be made in cyber-sex entertainment, including full immersion simulations, will encourage rapid development and deployment. ${ }^{8}$ Social critics will have a field day. They will be ignored.

In "The Next 1,000 Years: The 'Big Five' Engines of Economic Growth," Graham T. Molitor predicted that "leisure-oriented businesses-everything from bars to video stores to opera houses-will account for $50 \%$ of the U.S. gross national product shortly after 2015." ${ }^{\prime 9}$ In his scenario, the Leisure Era will replace the Information Age, which has been dominant since $1976 .^{10}$

The huge investments made in the development of virtual reality games and experiences will benefit individuals and organizations in the information industry. The cost of virtual reality equipment will eventually come down to a level that permits their purchase for educational purposes. This author speculates that the number of rudimentary virtual reality learning tools will increase considerably in the next two decades. Fully developed models will not be available until much later, and their utility will be vigorously 
debated. By mid-century, sophisticated virtual reality learning tools should be commonly available.

Arguably, efforts to create useful computer-based learning environments have not been particularly successful. This will change in the near future. For example, it is easy to imagine a MUD chat room for people who want to learn a foreign language. The visual configuration of the chat room would change based on the lesson. Today, we are in the bank exchanging currency. Tomorrow, we will be in the dining room simulating the enjoyment of good French cooking with appropriate wines. Shortly, the technology will allow substitution of voice communication for textual communication. Speech-understanding systems are currently on the market. They are being refined, and voice recognition error rates are declining. The airline industry is especially interested in applying speech-understanding systems for flight information and ticket purchasing. ${ }^{11}$ Other features of equal or greater importance will offset many of the impersonal qualities of the computer. Although this author worries regularly about the negative impact of the anticipated decreases in forms of personal face-to-face interaction, he realizes that the overall increase in meaningful human communication, albeit at a distance, will expand at an awe-inspiring rate.

\section{We get into the habit of clinging to knowledge bits and lose our feel for the wisdom behind knowledge.}

The uses of information will change dramatically in the early years of the twenty-first century. There are many reasons for this. First, the total amount of information continues to increase rapidly. This outpouring overwhelms many people. As roles become more specialized, knowledge becomes more fragmented. Information is rendered obsolete more quickly as the rate of change continues unimpeded. William E. Holal, Michael D. Kull, and Ann Leffmann predicted that “The early 2010s will witness the most striking technological advances in terms of number, scope, and sophistication that civilization has ever seen."12 Meanings will date faster, images will fly by faster, focus of attention will narrow, and information content will erode further as the products of media are commercialized further.

The structure of the book imposes limits on the author and the reader. "Gregory Ulmer explains ... four millennia during which anything in language that 'resisted linearization was suppressed. Briefly stated, this suppression amounts to the denial of the pluridimensional character of symbolic thought originally evident in the "mythogram" (Leroi-Gourhan's term), or nonlinear writing (pictographic and rebus writing).'"13 The spatio-temporal qualities of the computer encourage the use of intuition and visualization. ${ }^{14}$ Silvio Gaggi saw additional advantages to digital writing. It escapes the psychic framework of the book and "recaptures some of the immediacy-the apparent near-identity of thought and symbolization-that characterized oral culture." 15

William Crossman takes Gaggi's oral culture characterization in a surprising new direction. He discards writing. In "The Coming Age of Talking Computers," Crossman suggested that "The voice-in/voice-out (VIVO) computer will be the last nail in written language's coffin. By enabling us to access stored information orally-aurally, talking computers will finally make it possible for us to replace all written language with spoken language. We will be able to store and retrieve information simply by talking, listening, and looking at graphics not text. With this giant step forward into the past, we're about to recreate oral culture on a more efficient and reliable technological foundation." 16 The shock value of this particular prediction is quite high. The tendency may be to reject it out of hand. This author is hesitant to do so only because of estimates that "eighty percent of adults worldwide are functionally nonliterate." ${ }^{\prime 17}$ Talking to a computer may have substantial appeal and efficacy for those who are nonliterate and may provide them with new-found capabilities. 
As the global economy expands, job dislocations and career shifts will increase. Lifelong learning has become a necessity; however, financial demands on the individual reduce the time available to prepare for additional careers. Efficiency and utilitarian values will reduce the perceived relevance of a liberal arts education. There will be a greater emphasis on experiential skills in the face of a rapidly changing work environment. The current emphasis on quick results will accelerate. Individuals are likely to be satisfied with bits and pieces of information. Less and less time will be devoted to the aggregation of bits and bytes of information into knowledge components or higher forms of intelligence. People will make do and build psychologically secure rationalizations around these practices. There will be efforts to counter many of the negative trends noted in information-seeking and use patterns. These efforts will have greater importance in the future than in the past because the need for unifying perspectives is reaching a critical stage. Fragmentation is apparent in the social fabric as interest groups multiply and as common-ground understandings dwindle.

Information is touted as the sine qua non of the twenty-first century. Despite vast increases in the amount of information available, many individuals appear to be less capable information users. Jean Baudrillard suggested that information devours content. ${ }^{18}$ Michael Heim anguished over the condition of our information scene: "Infomania erodes our capacity for significance. With a mind-set fixed on information, our attention span shortens. We collect fragments. We become mentally poorer in overall meaning. We get into the habit of clinging to knowledge bits and lose our feel for the wisdom behind knowledge. In the information age, some people even believe that literacy or culture is a matter of having the right facts at our fingertips..$^{19}$ Our survival as a profession will be influenced by our ability to overcome the negative characteristics of the bits and bytes syndrome. This subject is discussed further in the next section.
We live at a critical juncture in human history. The opportunities are glorious, the challenges daunting. We seem to be overdeveloped economically and technologically, but underdeveloped socially, culturally, and politically. But this can change. That is, the condition has not been unvarying throughout history. In A World Made by Men, Charles Radding portrayed seventeenth-century Europe as economically underdeveloped, but quite sophisticated socially, culturally, and politically. ${ }^{20}$ People everywhere are struggling to make things better. They are struggling to build a new social fabric. They are struggling to find answers to the most difficult and perplexing ethical issues. We have our own struggles. This includes the struggle for survival.

\section{Libraries in the Future-Speculations}

No one else but we ourselves

handcuffed us, comfortably in the

face of our fear.

That's why we offer you our two

bound palms

instead of unfolded wings. ${ }^{21}$

$\sim$ Ivan Radoev

How would librarians be rated on an imaginary discontinuity scale? The scale goes from 0 to 10 . A rating of 0 means that a discontinuity does not exist for them. A rating of 10 means that there is a complete and unresolved break between the factors being considered (e.g., mind and body). It is difficult to conceive of anyone being either a 0 or a 10 . The themes are too deeply embedded in our humanity. As such, we are constantly engaged in a largely unconscious effort to find a sense of personal and professional balance.

So, what is the problem? Quite simply, our everyday ways of dealing with these discontinuities are not likely to be as satisfactory in the future as in the past. From this perspective, we should bring the discontinuities to a conscious level and develop viable approaches for resolving them or narrowing the gap.

The library world as we know it is being erased. The causes are external to the 
library, external to higher education. The effects are beyond our control. We are spectators. Nonetheless, we are free to discover new pathways and to begin the process of creating new forms in the verdure of a new world. Three points need to be made before proceeding further.

First, in the past librarians stood on the steps of the library. In the future the library will stand on the shoulders of librarians.

Second, librarians must begin to design an imaginative, easily identifiable space in cyberspace as the centrality of the library as a physical phenomenon slowly fades. This does not mean that libraries will be irrelevant or obsolete. It does mean that the services of librarians will be provided most effectively in a virtual environment. Librarians will construct the image of libraries to mirror the image of service they wish to promote.

Third, current service philosophies will have marginal utility in a full-scale virtual environment. As the twenty-first century progresses, librarians will deal with users almost exclusively in a virtual environment and face-to-face interchanges will become atypical. Attention to alternative philosophies is necessary. This includes replacing the historic value neutral approach with an innovative valueadded approach. Services focusing on the content and context of information will become increasingly desirable to users. The new value-added services customized to the individual user will thrust librarians into a more meaningful and sophisticated role as knowledge advisers and counselors.

\section{Time and Space}

The modern library originated in the late 1800 s. It has a proud heritage and is one of the country's most esteemed institutions. Books and buildings are predominant features in the public's perception of what constitutes a library. The building accommodates the collections and the users of those collections. Books and buildings are physical objects occupying definite and discrete places. They are unmistakable physical identifiers. The time and space considerations of librarians are defined and circumscribed by the libraries in which they work.

The library is a highly formalized physical operation. Discontinuities of time and space have rarely been allowed to intrude on the library environment. Things are fixed in space in a linear pattern. Time is carefully structured in or-

\section{In a keyword-based online environ- ment, traditional bibliographic structures with hierarchical, con- trolled vocabularies become less important.}

der to optimize the use of the library's resources. Library and unit hours and a wide array of policies and procedures impose limits on the user. Some of these limits will be irrelevant in cyberspace; remote users can access the Internet twenty-four hours a day. The Internet has not noticeably affected standard practices. An exception to this pattern is the widespread use of the Internet at reference desks.

Cataloging and classification provide the intellectual structure for the organization of materials. They facilitate access to the collections. In a keyword-based online environment, traditional bibliographic structures with hierarchical, controlled vocabularies become less important. Whether users will be more successful in retrieving relevant information as a result of these changes is unclear.

The modern library features collections acquired and available for use on-site. This is the ownership paradigm..$^{22}$ The assumption is that the physical collections will meet most user needs. Interlibrary borrowing is a backup system. This paradigm began to weaken when the funding for collections was unable to keep up with the cost of materials needed to support teaching and research. Interlibrary borrowing skyrocketed as a result of the need to cover the availability gaps. In the 1980s and 1990s, electronic access helped to alleviate somewhat the effects of the eroding adequacy of on-site collections. 
What happened next is illuminating. A number of people began to put three trends into clear perspective and came to a logical conclusion that was confirmed within a relatively few years. Trend one: There is no end in sight to the erosion in the funding necessary to maintain physical collections at previous levels. Trends two and three: Projections for the rapid growth of electronic information and the ever-increasing utility of this information for teaching and research are likely to prove accurate in the long term. The conclusion was simple. Access to information, rather than ownership of it, should be emphasized in the future. Access evolved quickly into the dominant paradigm. The access paradigm does not address the status of physical collections. Speed of access is an implied corollary: electronic speed, not land/air speed.

The ability to obtain not-owned information electronically without having to rely as heavily on owned information begins the process of disconnecting librarians from their fundamental time and space attachment to the library and its collections. This is of enormous significance. Librarians can perform some of their responsibilities in a nonphysical, invisible environment. Eventually, librarians will perform most of their responsibilities in this new virtual spacecyberspace.

The access paradigm is usually considered a central feature of the digital library. By digitizing select collections, remote users will obtain access to important collections previously available only to onsite users. The digital library imposes subtle shifts in the time and space orientations of librarians and users. The current image of the library as a physical manifestation will need to be transformed as its functions are increasingly performed in a virtual environment. Librarians will build these new structures, not construction workers.

The creation of a readily identifiable "intellectual and logical" cyberspace for libraries will be of the utmost importance within the next decade or two. This new space will be a critical identifier for users at a time decades from now when the physical library will be less visible to the public than the virtual library in the new cyberspace environment.

One might assume that the evolution of libraries along the lines suggested by the concept of the digital library would position us effectively for the future. It does not. Definitions of the digital library typically fail to provide a coherent service philosophy. ${ }^{23}$ The service features are primarily extensions of current philosophies disguised within a fashionable vernacular. The digital library replaces the physical object with the digital object. This remains a significant development, but the digital library as conceived is not responsive to the discontinuities described by observers outside the field of librarianship. ${ }^{24}$

Librarians are making reasonable efforts to adapt in response to their perceptions of the future. However, these efforts continue to tie us to the modern library, albeit digitized. If the discontinuities exist as described, the library of today is fated to shrink in importance. It will be a marginal institution by the year 2050 if radically different philosophies of service are not adopted in the next few decades. The process involves the social construction of a different type of institution based on new realities as we envision them. This is mandatory if the profession is to create a more viable and sustainable role in the twenty-first century.

\section{Mind and Body}

Computer use by librarians has exploded in the past five years. Librarians are deeply immersed in the process of constructing and maintaining thousands upon thousands of home pages. New software products appear at a dizzying rate. Librarians are hard-pressed to keep up with these new releases. One set of librarians struggles to learn HTML while another set discusses CCS and XML as HTML replacements. The virtual workspace is dynamic and turbulent. This may cause stress, cynicism, and anger; however, most librarians view the Internet as a new frontier. They are excited by it and embroiled in solving 
a vast array of thorny problems. The level of detail is extraordinary, and the amount of expertise shared by colleagues around the world is both spectacular and just plain wonderful.

\section{As librarians become immersed in cyberspace, the process of disembodiment accelerates.}

Librarians are beginning to see the outlines of a cyberspace world. They recognize the opportunities for serving their users better. On the Web4Lib list, Gerry McKiernan, curator of CyberStacks at Iowa State University, suggested the use of recommendation agents to facilitate the process of identifying "quality" resources. ${ }^{25}$ Recommendation agents present users with resources based on criteria established from an initial questionnaire and subsequent interaction with recommendations made by a recommendation service. McKiernan extended this concept to the area of collection development. He envisions a research interest profile (RIP) compiled by a content agent based on information gathered automatically from the home pages of a faculty member, departmental home pages, and other online sources (e.g., references cited in published works of faculty). Based on the RIP, search agents would locate materials for possible acquisition.

As librarians increase their responsibilities in virtual (invisible) space, their presence in real space decreases. As librarians become immersed in cyberspace, the process of disembodiment accelerates. The actions of the mind become more important while those of the body become less important. This is not a new phenomenon. Technology frees us from the body. In academia we normally praise "a life of the mind." The concept of the ivory tower refers to a freedom from everyday practical concerns. These concerns typically connect to a physical activity. Some believe the movement toward a higher level of human (mental) consciousness and a lower level of physical activity marks the normal course of human evolution.
Feelings of disembodiment are likely to appear in the middle stages of existence in a virtual environment. Eventually, a natural process of adaptation will occur. Some librarians will experience a healing closure in which the mind and the body are satisfactorily reconciled to the new environment. Other librarians will not like the new environment and will remain uncomfortable with it, especially if their personal feelings of discontinuity remain pronounced.

The discontinuity between the mind and the body will cause divisions in our society and will challenge our sense of being. One can anticipate a significant growth in social movements that encourage us to relate more closely to nature, warning us about the dangers of ignoring our biological roots. On the other hand, a great Indian master once said, "The mind creates the abyss, and the heart crosses it." 26

\section{Real and Virtual}

Some of the concepts discussed in this article are slippery and hard to encompass. For example, the closer one gets to describe the concepts of real and virtual, the more one realizes the limits of language and the danger of falling into a series of semantic traps. For the sake of simplicity real and virtual will be treated as mutually exclusive. From this perspective, it follows that as virtual experiences increase, real experiences decrease. The real is unmediated. Take off your dark glasses or tinted lenses. The sunrise on the horizon is real. The one on television is a representation of reality. This distinction contrasts direct experience of an object with indirect experience through a form of mediation. Mediated experiences have a greater potential for distortion than unmediated experiences.

As we work on the computer, watch television, read a book, or look at a photograph, we enter into virtual environments. ${ }^{27}$ The time people spend in virtual environments at work and at home will increase dramatically in the next few de- 
cades. Some people already spend more time in virtual environments than in all other conscious experiences (e.g., six hours in front of the computer at work and four hours in front of the television at night). The virtual environments include those driven by simulation and immersive technologies. The usefulness and practicality of simulation technologies for training people have been proved in many settings. It remains to be seen how well they will work in college classrooms.

\section{Librarianship is in a position similar to the modernists. What we offer will not be sufficient in the future.}

Librarians work in the world of information. So, to some degree, the current emphasis on the centrality of information in society does not find us out of step. Many of us have observed the phenomenal growth in the amount of information since the early 1960s when the term information age was formulated. We have also watched as the information as a commodity concept gained widespread acceptance. Librarians have both applauded and criticized this development. Interestingly, commodities, once conceived of as purely physical, now include nonphysical phenomena.

Librarians work with physical objects. With these objects we provide assistance to readers in search of information. The printed word has preeminence over other forms of communication. Libraries support the mission and goals of the college or university. The search for truth or objectivity is an essential and defining value. Concepts of reason, validity, verification, replication, unification, and order are central to the standard modes of thinking in higher education. These pre-twentiethcentury values are deeply embedded in the intellectual core of librarianship. The search for truth led to discoveries that undermined the foundations upon which many of the preexisting values were based. The theories of Darwin, Freud, Einstein, Heisenberg, and countless others opened up entirely new ways of look- ing at the world. Reason faced the irrational. Order and stability tilted with chaos. Unity was divided by the fragmentary. Consciousness was disturbed by the appearance of the unconscious.

The adherents of the old rejected the new and failed to make the necessary accommodations. The modernists reject. They offer the past. The postmodernists destroy. They offer the future. Librarianship is in a position similar to the modernists. What we offer will not be sufficient in the future. We must admit to multiple realities and virtual realities and users who will occupy a mixture of realities and time/space orientations beyond the edge of current thinking.

The process of reading is very different from the process of viewing television. Librarians generally applaud the urge to read and abhor the representational values of television. Many librarians are disturbed by the impact of television on America. As electronic images become more and more ubiquitous, the study habits of students seem to suffer. Shorter attention span, inadequate preparation, a grade and not a learning orientation, and an interest in the surface and not the substance of things are among the newer ways of thinking linked to students. There is a gulf between us. The integration of computers and television and the introduction of forms of immersive reality may accelerate the divisions between our institution as currently designed by librarians and our younger user groups.

The use patterns of information seekers will change in response to motivation and available technology. People in the future will have less time to explore issues in depth and will tend to work on the surface of things. Results will be expected quickly and tolerance for traditional time lines for the delivery of products and services will diminish. Librarians will have to adapt to these new expectations and eliminate many of the restrictions currently imposed on users. The types of service and product support available to library users today bear little resemblance to the customer-client philosophy that has spread rapidly through- 
out the industrial and service sectors in the past twenty years. In library literature and at conferences and workshops, many librarians have expressed an urgent need for academic librarianship to assume a strong customer-client orientation. Few changes have been made in this direction.

As television continues to distort reality, simulations become valuable learning tools, and the virtual world becomes increasingly meaningful in the lives of individuals, understandings about the nature of reality will undergo dramatic changes. The practical, hard-edged reality of the library will seem particularly anachronistic. The rapid gains made by librarians in using the Internet will mitigate some of the problems. However, the Internet is not what Gibson and the current wizards of computer science consider a true virtual reality environment. Indeed, the current browser environment has been described as "archive like." The Internet is like a foot on the shoreline testing the waters of a vast ocean in the process of formation-cyberspace.

The modern library and the neutrality orientation of the library profession reinforce the contemporary emphasis on facts as distinct from the higher aspects of intellectual synthesis and understanding. ${ }^{28}$ Real life has a wholeness we have never truly appreciated. Our reductionist thinking has predominated. The digital library provides additional stimulus in this direction. This is both understandable and unfortunate. It is understandable because the profession dwells on the details of things as the basic rationale for its existence. We build a foundation from the details and construct our services and programs accordingly. It is unfortunate because our vision of what constitutes a foundation is unnecessarily narrow, thereby limiting the types of services and programs we will consider offering. Our focus on digits and digitizing is consistent with library practices of the past hundred years. This positions us in a reasonable manner for the short term, but in the long term this approach is likely to limit our search for alternatives that will en- able us to avoid becoming a marginal profession bypassed by others who offer more.

As the concept of a single reality is replaced by the concept of multiple realities, the intellectual foundation of the library is brought into question. Virtual worlds and possible worlds, cyberspace and the new writing spaces, and a host of other developments described and critiqued by postmodernist writers undermine the static, hierarchical and linear nature of libraries. Modernist writers struggle to hold onto a set of pre-twentieth-century values and the power they share with others wielding these values in the political and business sectors. The conflict of ideas is titanic. Indeed, one can easily describe the gap between the positions as a form of discontinuity with vast implications. Struggles over the literary canon, diversity, and environment can arguably be perceived as a wish by some to hold onto a way of being that is no longer relevant to the realities of the twenty-first century. The modernists among us typically hold views whose problem-solving capability is exhausted, whose answers are flawed, and whose attitudes are often as disrespectful of developing values as they are respectful of historical ones. It is time to disassemble the postmodernist critique and the modernist ideals in order to create a new synthesis relevant to the current realities. In the meantime, the lyrics are catchy and the tune is amusing.

\section{Librarians are making significant personal investments in learning new skills.}

As a cultural icon with a strong heritage, the modern library may not be able to keep step with the processes of change. The public may not allow the library to be transformed in ways necessary for it to survive as a viable institution in the new millennium. The Benton Foundation Report on Libraries in the Digital Age suggests that libraries may not have the public's support for transformational activities. "Most telling, participants said 
libraries should not take the lead in providing services in the digital age. In fact, they thought libraries should take a reactive role, adapting to, rather than pioneering, new technologies." 29 The authors of the report do not accept this approach and recommend another: "Now is the time for libraries to seize the opportunity and define their role with an aggressive public education campaign." ${ }^{30}$ The approaches discussed in this article go far beyond the changes mentioned in the Benton Report. Indeed, the time is not right for academic librarians to announce a shift. This would be entirely premature. Librarians remain wedded to the library. However, librarians can plan for the day when they will take over and the library will assume a secondary role.

\section{Humans and Technology}

The book and the periodical as we know them today are the products of more than four hundred years of development. Their structure and other defining features have helped to shape our culture and been shaped by it. The computer has a completely different structure. Entirely new creative possibilities open up. The combination of print, sound, and image is only the most obvious. Eventually, the writing space of the computer will reshape reality just as the innovation of the book altered the reality of earlier societies. ${ }^{31}$ We have seen little reshaping thus far.

Librarians have taken important steps in adapting to many of the computer- and communication-related technologies. Librarians are making significant personal investments in learning new skills. The Internet offers a wonderful training ground. It is nonjudgmental and forgiving. One moves simply and easily down a multitude of pathways. Some are dead ends whereas others keep opening up in a seemingly endless variety of opportunities. It is easy to be excited about the wealth of the information to be discovered searching the Net. How do we harness this information for the benefit of our users? This is one of the principal questions being addressed today by reference librarians and others responsible for providing access to the world of information.

There is no indication librarians have adapted a cyborg attitude as part of their accommodations to technology. Machines are viewed as convenient tools. We behave as if we are entirely free to choose and discard what we wish. This is untrue. We are not always free to choose. The Internet is only the latest example. The imagination of the public was stirred by a continuing string of media stories about the Internet and its success. Success bred success and the Net was thrust upon us. It became unavoidable, inescapable. Some librarians were ahead of the curve on this one. Many were not. The tired old arguments were no longer acceptable. They had become untenable. Most innovations are subtler in their impact.

The cyborg is an alien concept. Most people will reject any status that assumes they are technologically dependent. No nonhuman influence will gain their acceptance. Most believe they can and should control nature and make all other earthly objects do their biding without any reciprocity or sharing in power or influence or control. Pride of accomplishment is allied with a deep-seated human arrogance.

As technological dependency increases, we are likely to witness efforts to deny, avoid, minimize, or step away from it. Our sense of being will be challenged and our sense of self will be threatened. Librarians will be affected by this as much as anyone. Success with genetic engineering and computer intelligence will aggravate already-existing discontinuities and will have serious psychological consequences. Avoidance may be advantageous for a while, but it is never healthy per se and remains less so as time passes without resolution of the problem.

If librarians are unable to find comfortable roles in cyberspace with new valueadded products and services, it will be difficult to maintain the relevance of librarianship as it exists today. However, there will be a wonderful assortment of new technologies available to us. These allow us to move well beyond our cur- 
rent abilities and can lead to notable revisions in our thinking about our role in the future. A wide array of intelligent agents or bots will assist librarians in offering students and faculty customized services and products far beyond today's generalized approaches. ${ }^{32}$

\section{The construction of new libraries will diminish, and within twenty- five years the physical symbol of the library will no longer be a viable representation of functionality.}

We will be able to compile user profiles and obtain use information with relative ease. This will allow us to anticipate needs and to be proactive in our relations with students and faculty. Librarians will be able to create multiuser domains with comfortable interaction zones for participants and a set of virtual services and products responsive to those who are seeking information or requesting assistance.

\section{Conclusion}

We've inherited hope-

the gift of forgetting.

You'll see how we give

birth among the ruins. ${ }^{33}$

$\sim$ Wislawa Szymborska

The pieces of the puzzle have been laid out. They remain vague with fuzzy shapes and indistinct colors. The mystery about them is likable. This is reasonable because the process has been speculative. We use what we want in life and set aside the rest. Add your own puzzle pieces. Try to assemble them. They beg for attention. They do not want to be set aside.

The pieces are fragments representing four discontinuities with respectable traditions reaching into the distant past. Philosophers, scientists, wise men and women, and other seekers of knowledge have wrestled with them for centuries. The discontinuities are being exacerbated by the conditions discussed in this article. The nature of the relationship between the pieces and the future may only be understood when the future has become the past. For some things, that will be too late. For most, it will make little difference.

How do libraries fit in here? Well, if pushed to make a prediction, this author would say that libraries as we know them will continue to have a role as archives of recorded knowledge. The construction of new libraries will diminish, and within twenty-five years the physical symbol of the library will no longer be a viable representation of functionality. The construction of a recognizable virtual library or librarian activity space will be necessary to avoid a disastrous blurring of our professional image. The time is right, however, for librarians. As the millennium unfolds, we will discover a new source of energy and renewal. Ourselves. We will be the living force. We will remake the library in our image. Will we take this path? One can be hopeful, but the prospects are not entirely favorable. Libraries will continue to exist. They will continue to be a symbol. If we remain tied to them in the old ways, we will share their fate. ${ }^{34}$

Fiction writers, social critics and observers, French philosophers, and MIT professors portray the discontinuities in vivid language. Their intensity is high. Their words prod and poke at us. They seem to expect reactions. The author has set aside some pieces that were bland in favor of the more colorful. His motivation was simple. Bold colors are easier to see.

The new millennium is going to be full of color. Black and white will not go away. Old movies, classic photographs, and print on the page will retain their allure and glamour. They are part of us, part of our history. School kids will choose many colors when they print. Cost factors are changing. So are the choices. If this manuscript were submitted in brown on white paper, what might the editor do with it?

\section{Notes}

1. Jay David Bolter, Writing Space: The Computer, Hypertext, and the History of Writing (Hillsdale, 
N.J.: Lawrence Erlbaum, 1991), ix.

2. George P. Landow, Hypertext: The Convergence of Contemporary Critical Theory and Technology (Baltimore: Johns Hopkins Univ. Pr., 1992), 2-3.

3. Sherry Turkle, Life on the Screen: Identity in the Age of Internet (New York: Simon \& Schuster, 1995), 26.

4. Scott Bukatman, Terminal Identity: The Virtual Subject in Postmodern Science Fiction (Durham: Duke Univ. Pr., 1993), 64.

5. Ibid., 30.

6. Michael Dertouzos, What Will Be: How the New World of Information Will Change Our Lives (San Francisco: HarperCollins, 1998), 70.

7. Jeremy Rifkin, "Patent Pending," Mother Jones 23, no. 3 (May-June 1998): 50.

8. Dertouzos, What Will Be, 142-48.

9. Graham T. Molitor, "The Next 1,000 Years: The 'Big Five' Engines of Economic Growth," Futurist 33, no. 10 (Dec. 1999): 13-14.

10. Ibid., 14.

11. Dertouzos, What Will Be, 58-64.

12. William E. Holal, Michael D. Kull, and Ann Leffmann, "Emerging Technologies: What's Ahead for 2001-2030," Futurist 31, no. 5 (Nov.-Dec. 1997): 23.

13. Landow, Hypertext, 43.

14. Michael Heim, The Metaphysics of Virtual Reality (New York: Oxford Univ. Pr., 1993), 30; Turkle, Life on the Screen, 52.

15. Silvio Gaggi, From Text to Hypertext: Decentering the Subject in Fiction, Film, the Visual Arts, and Electronic Media (Philadelphia: Univ. of Pennsylvania Pr., 1997), 13. See also the special issue of Modern Fiction Studies 43, no. 3 (fall 1997) on the subject of "Technocriticism and Hypernarrative."

16. William Crossmam, "The Coming Age of Talking Computers," Futurist 33, no. 10 (Dec. 1999): 42.

17. William Crossman, “'William Crossman Responds' to Dan Johnson's 'Literacy Will Survive: An Alternative Scenario,'" Futurist 33, no. 10 (Dec. 1999): 47.

18. Jean Baudrillard, In the Shadow of the Silent Majorities, trans. Paul Foss, Paul Payton, and John Johnston, Foreign Agents Series, ed. Jim Fleming and Sylvere Lotringer (New York: Semiotext[e], 1983), 101.

19. Heim, Metaphysics of Virtual Reality, 10.

20. Charles Radding, A World Made by Men: Cognition and Society, 400-1200 (Chapel Hill, NC: Univ. of North Carolina Press, 1985), 261.

21. Excerpt from the poem "Ballad for the Future" by Ivan Radoev, in Clay and Star: Contemporary Bulgarian Poets, trans. and ed. Lisa Sapinkopf and Georgi Belev (Minneapolis, Minn.: Milkweed, 1992), 58.

22. The paradigms of ownership and access are used as they have been described in library literature. These paradigms fail to meet the widely accepted criteria discussed by Thomas Kuhn in his classic work, The Structure of Scientific Revolutions. Furthermore, the core of logic underpinning these two so-called paradigms is peculiar. Recorded knowledge (owned) is a product. Access is a process. Recorded knowledge without access is as ludicrous as access without recorded knowledge (owned or not owned). Each requires the other and is incomplete without it. Moreover, it may be reasonable to assume that the field of librarianship is at a nonparadigmatic stage. Indeed, "paradigm shiftlessness" is considered one mark of the twentieth century by Theodor Nelson, "'Where the Trail Ends,' A Symposium in Honor of Vannevar Bush on the $50^{\mathrm{th}}$ Anniversary of 'As We May Think.'” Massachusetts Institute of Technology, Cambridge, Oct. 12, 1995.

23. This theme is developed by Francis Miksa and Philip Doty, "Intellectual Realities and the Digital Library," in Proceedings of Digital Libraries '94: The First Annual Conference on the Theory and Practice of Digital Libraries (College Station, Tex.: Texas A\&M University, 1994). Available online at: http:/ / csdl.tamu.edu/DL94/paper/miksa.html; Francis Miksa, "The Cultural Legacy of the 'Modern Library' for the Future," address to the annual meeting of the Association for Library and Information Science Education, San Antonio, Tex., Jan. 17, 1996. Available online at: "The Challenge of a New Environment," http://www.gslis.utexas.edu/ miksa/nine.html; Peter Lyman, "What Is a Digital Library? Technology, Intellectual Property, and the Public Interest," Daedalus 125, no. 4 (fall 1996): 2, 11.

24. Peter Neurnberg et al., "Digital Libraries: Issues and Architectures." Available online at: http://csdl.tamu.edu/DL95/papers/nuernberg/nuernberg.html. See also special issue on "Digital Libraries: Global Scope, Unlimited Access," Communications of the ACM 41, no. 4 (Apr. 1998): 49-98.

25. Gerry McKiernan, "Agent-based Cooperative Collection Development." Available from gerrymck@iastate.edu.

26. Jack Kornfield, A Path with Heart (New York: Bantam Bks., 1993), 50. 
27. Virtual reality can be defined as the "simulation of the real by technological means using multi-media inputs." James Watson and Anne Hall, A Dictionary of Communication and Media Studies, $4^{\text {th }}$ ed. (London: Arnold, 1997), 242. Interactive and 3-D attributes are sometimes assumed. Some of the media I have included under the heading of virtual reality (i.e., television, book, and photograph) would be excluded if these attributes were added.

28. Archie Dick, "Library and Information Science as a Social Science: Neutral and Normative Conceptions," Library Quarterly 65, no. 2 (Apr. 1995): 217-18.

29. "Buildings, Books, and Bytes: Libraries and Communities in the Digital Age," Library Trends 46, no. 1 (summer 1997): 205. This is the full report originally published by the Benton Foundation and funded by the W. K. Kellogg Foundation.

30. Ibid., 216.

31. Tom McArthur, Worlds of Reference: Lexicography, Learning, and Language from the Clay Tablet to the Computer (New York: Cambridge Univ. Pr., 1986), 7.

32. Communications of the ACM, 37, no. 7 (July 1994) contains several articles on intelligent agents. Pattie Maes's "Agents that Reduce Workload and Information Overload" (31-40, 146) describes some practical applications currently in use.

33. Wislawa Szymborska, "Notes from a Nonexistent Himalayan Expedition," in View with a Grain of Sand: Selected Poems, trans. Stanislaw Baranczak (New York: Harcourt Brace \& Company, 1995), 4.

34. "It is important that librarians confront the fact that our profession could become dangerously marginal in academic life if we are not more responsive to actual user needs and preferences." Virginia Massey-Burzio, "From the Other Side of the Reference Desk: A Focus Group Study," Journal of Academic Librarianship 24, no. 3 (May 1998): 155. 